\title{
Osmium-Mediated Direct C-H Bond Activation at 8-Position of Quinolines
}

\author{
Miguel A. Esteruelas, ${ }^{*}$ Carmen Larramona, Enrique Oñate
}

Departamento de Química Inorgánica, Instituto de Síntesis Química y Catálisis Homogénea (ISQCH), Centro de Innovación en Química Avanzada (ORFEO-CINQA), Universidad de Zaragoza-CSIC, 50009 Zaragoza, Spain.

\author{
Supporting Information Placeholder
}

\begin{abstract}
The metal-mediated direct $\mathrm{C}-\mathrm{H}$ bond activation at 8-position of quinolines, which is the essential step for the functionalization of this bond, is promoted by the hexahydride $\mathrm{OsH}_{6}\left(\mathrm{P}^{\mathrm{i}} \mathrm{Pr}_{3}\right)_{2}$. This complex activates quinoline and 2-, 3-, 6- and 7methyl-quinoline to afford the classical trihydride derivatives $\mathrm{OsH}_{3}\left\{\kappa^{2}-\mathrm{C}^{8}, \mathrm{~N}-(\right.$ quinolinyl $\left.)\right\}\left(\mathrm{P}^{\mathrm{i}} \mathrm{Pr}_{3}\right)_{2}$ and $\mathrm{OsH}_{3}\left\{\kappa^{2}-\mathrm{C}^{8}, \mathrm{~N}-(\right.$ quinolinyl-n$\mathrm{Me})\}\left(\mathrm{P}^{\mathrm{i}} \mathrm{Pr}_{3}\right)_{2}(\mathrm{n}=2,3,6,7)$, containing a four-membered heterometalaring.
\end{abstract}

The $\mathrm{C}-\mathrm{H}$ bond activation ${ }^{1}$ is among the most relevant metalmediated $\sigma$-bond activation processes due to its connection with the functionalization of inert $\mathrm{C}-\mathrm{H}$ bonds ${ }^{2}$ and as an intermediate step in the preparation of new materials. ${ }^{3}$ A major goal is to control the selectivity of the process when $\mathrm{C}$-H bonds of similar dissociation energies are present in the same substrate, in order to reduce the environmental impact. Particularly relevant is to achieve the regioselective $\mathrm{C}-\mathrm{H}$ cleavage at unfavorable sites.

Quinoline is an important scaffold found in a wide range of natural products, with interesting biological activity, and in functional materials ${ }^{4}$. The functionalization of the positions of the nitrogen containing ring is easier than those of the homocyclic ring, ${ }^{5}$ in particular the $\mathrm{C}-\mathrm{H}$ bond at 2 -position because of its weakness and the strengthens of the $\mathrm{M}-\mathrm{CN}$ bond in the intermediates resulting from its activation. ${ }^{6}$ In contrast to the $\mathrm{C}-\mathrm{H}$ bond at 2-position, the functionalization of the $\mathrm{C}-\mathrm{H}$ bond at 8-position, in the homocyclic ring, has been only achieved twice. In 2014, Steel, Marder, Sawamura and co-workers reported site selective $\mathrm{C}-\mathrm{H}$ borylation of quinoline derivatives at this position by using a silica-supported phosphine-iridium system $^{7}$ whereas, in 2011, Chang and co-workers described a protocol for the regioselective direct arylation of quinolines at the 8-position employing a $\mathrm{Rh}_{2}(\mathrm{OAc})_{4}(\mathrm{NHC})$ compound. $^{8}$ Given the dinuclear character of the catalyst precursor, they suggested the formation of bimetallic intermediates containing a bridge quinolinyl group, resulting from the $\mathrm{N}$-coordination and $\mathrm{C}^{8}-\mathrm{H}$ bond activation of the quinolines across the $\mathrm{Rh}-\mathrm{Rh}$ bond of the catalyst. A similar type of addition had been previously documented by Rosenberg and co-workers to the metal cluster $\mathrm{Os}_{3}(\mathrm{CO})_{10}\left(\mathrm{CH}_{3} \mathrm{CN}\right)_{2}$ (Scheme 1), during mechanistic study on the heterogeneously catalyzed hydrodenitrification of the heterocycles. ${ }^{9}$ The observation that some mononuclear precursors also showed significant catalytic activity and regioselectivity led to Chang and co-workers to speculate that a mononuclear four-membered heterometalacycle could be also a plausible intermediate. ${ }^{8}$ Although a few rings of this type are known, ${ }^{10}$ the direct $\mathrm{C}$-H bond activation at 8 -position of quinolines promoted by a mononuclear species was unprecedented until now.

Saturated transition metal polyhydride complexes have the ability of losing molecular hydrogen to afford unsaturated species, which coordinate and subsequently activate $\sigma$-bonds. In agreement with this, the hexahydride complex $\mathrm{OsH}_{6}\left(\mathrm{P}^{\mathrm{i}} \mathrm{Pr}_{3}\right)_{2}$ (1) has shown to be active for the cleavage of $\mathrm{C}-\mathrm{H}$ bonds of a wide range of organic molecules. ${ }^{11}$ In the search for the direct $\mathrm{C}-\mathrm{H}$ bond activation at 8-position of quinolines, we have investigated the reactivity of $\mathbf{1}$ towards these heterocycles. In this communication, we report the first direct $\mathrm{C}-\mathrm{H}$ bond activation at 8-position of quinolines, promoted by a mononuclear complex, which is important because gives a clue on the nature of the active species for this challenging reaction.

The reactions were carried out in toluene under reflux. Treatment of 1 with 1.0 equiv of quinoline, for $7 \mathrm{~h}$, under these conditions led to classical trihydride $\mathrm{OsH}_{3}\left\{\kappa^{2}-\mathrm{C}^{8}, \mathrm{~N}-\right.$ (quinolinyl) $\}\left(\mathrm{P}^{\mathrm{i}} \mathrm{Pr}_{3}\right)_{2}$ (2), which was isolated as an orange solid in about $70 \%$ yied. The reaction is compatible with a methyl group at different sites of both rings of the substrate, including the adjacent position to the metalated carbon atom $\left(\mathrm{C}^{7}\right)$. Thus, the addition of 1.0 equiv of 2-, 3-, 6- and 7-methylquinoline to the toluene solutions of $\mathbf{1}$ affords the respective methylsubstituted derivatives $\mathrm{OsH}_{3}\left\{\kappa^{2}-\mathrm{C}^{8}, \mathrm{~N}\right.$-(quinolinyl-n$\mathrm{Me})\}\left(\mathrm{P}^{\mathrm{i}} \mathrm{Pr}_{3}\right)_{2}(\mathrm{n}=2(3), 3(4), 6(5), 7(6))$, as orange solids, in $60-75 \%$ yield (Scheme 2 ).

\section{Scheme 1. $\mathrm{C}^{\mathbf{8}}$-H Bond Activation of Quinoline Promoted by} the Metal Cluster $\mathrm{Os}_{3}(\mathrm{CO})_{10}\left(\mathrm{CH}_{3} \mathrm{CN}\right)_{2}$

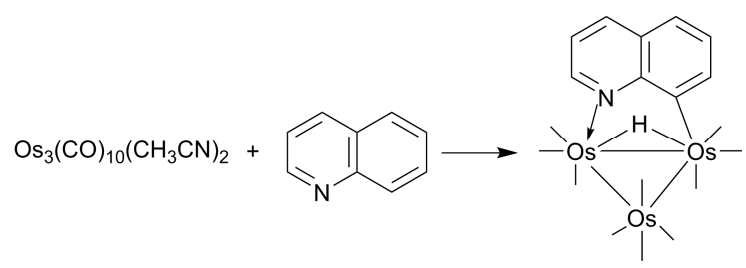


Scheme 2. $C^{8}-\mathbf{H}$ Bond Activation of Quinolines Promoted by $\mathrm{OsH}_{6}\left(\mathrm{P}^{\mathrm{i}} \mathrm{Pr}_{3}\right)_{2}(1)$



2
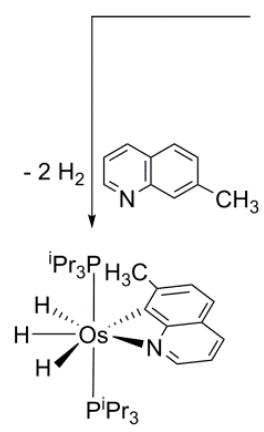

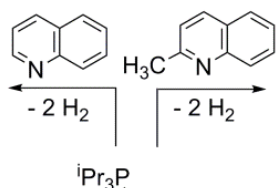

$\left.\mathrm{H}_{1, \ldots}\right) \mathrm{H}$
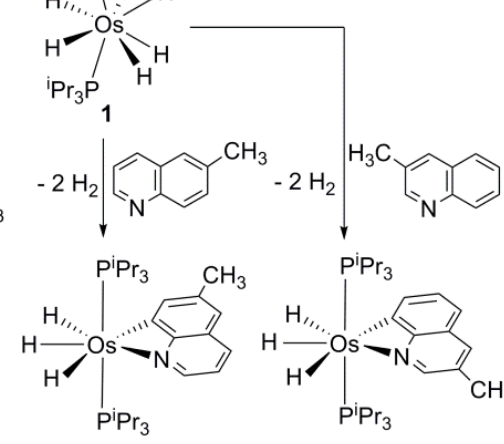

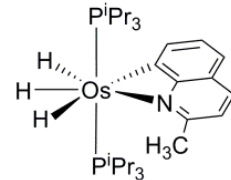

3

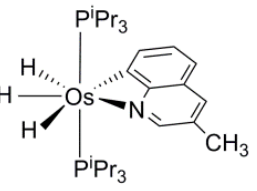

The direct $\mathrm{C}-\mathrm{H}$ bond activation at 8 position of the heterocycles was confirmed by means of the X-ray structures of $\mathbf{2}$ and 4, which proved the formation of the four membered heterometalacycle (Figure 1). The coordination polyhedron around the metal center of both compounds can be rationalized as a distorted pentagonal bipyramid with the phosphines occupying axial positions. The metal coordination sphere is completed by the metalated heterocycle, with acts with C-Os-N bite angles of $65.7(5)^{\circ}$ in 2 and $62.09(17)^{\circ}$ and $62.52(16)^{\circ}$ in $4,{ }^{12}$ and the hydride ligands separated about $1.7 \AA$. The ${ }^{31} \mathrm{P}\left\{{ }^{1} \mathrm{H}\right\},{ }^{13} \mathrm{C}\left\{{ }^{1} \mathrm{H}\right\}$ and the ${ }^{1} \mathrm{H}$ NMR spectra of 2-6 in toluene- $\mathrm{d}_{8}$ are consistent with this ligand distribution. In agreement with the presence of equivalent phosphines, the ${ }^{31} \mathrm{P}\left\{{ }^{1} \mathrm{H}\right\}$ NMR spectra contain a singlet between 28 and $31 \mathrm{ppm}$ whereas the $\mathrm{C}^{8}$-metalated resonance appears as a triplet $\left(\mathrm{J}_{\mathrm{C}-\mathrm{P}} \approx 8 \mathrm{~Hz}\right)$ between 146 and $150 \mathrm{ppm}$, in the ${ }^{13} \mathrm{C}\left\{{ }^{1} \mathrm{H}\right\}$ NMR spectra. The ${ }^{1} \mathrm{H}$ NMR spectra at $203 \mathrm{~K}$ show three high field resonances at about $-5.5,-13.1$ and $-13.9 \mathrm{ppm}$, in a 1:1:1 intensity ratio, as expected for three inequivalent hydride ligands. The signals at about -5.5 and $13.9 \mathrm{ppm}$ coalesce between 233 and $243 \mathrm{~K}$ to afford a single resonance at temperatures higher than $243 \mathrm{~K}$; Figure 2 shows the high field region of the spectrum of $\mathbf{2}$ as a function of the

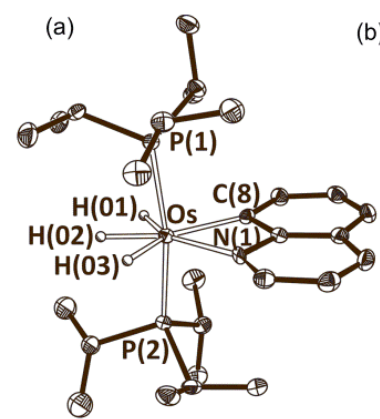

(b)

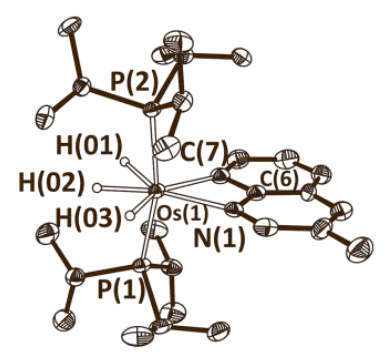

Figure 1. X-ray crystal structures of 2(a) and 4(b). The thermal ellipsoids are scaled at $50 \%$ probability level. Hydrogen atoms are omitted for clarity. Selected bond lengths ( $\AA)$ : 2: Os-N(1), 2.238(6); Os-C(8), 2.145(8); 4: Os(1)-C(7), 2.135(5), 2.141(5); Os(1)-N(1) 2.223(4), 2.234(4).

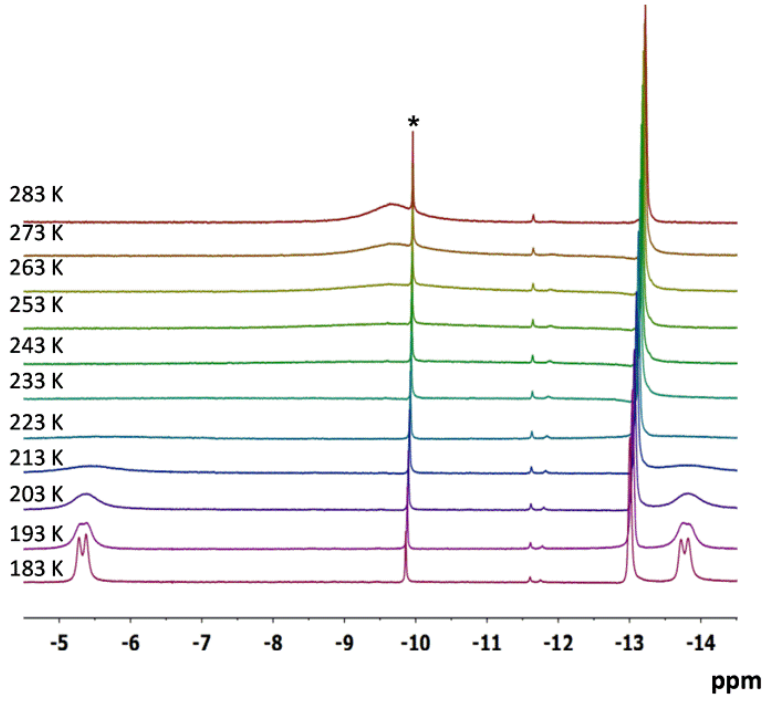

Figure 2. Variable temperature ${ }^{1} \mathrm{H}\left\{{ }^{31} \mathrm{P}\right\}$ NMR spectrum (400 $\mathrm{MHz})$ in the high field region of complex $2\left(* \mathrm{OsH}_{6}\left(\mathrm{P}^{\mathrm{i}} \mathrm{Pr}_{3}\right)_{2}\right)$.

temperature. The behavior observed for these resonances is indicative of a thermally activated site exchange process involving the corresponding hydrides, which occurs with an activation energy of about $10 \mathrm{kcal}^{\mathrm{mol}}{ }^{-1}$. The exchange mechanism should imply Os-H stretching, $\mathrm{H}-\mathrm{H}$ shortening and subsequent rotation of the resulting dihydrogen. So, the ${ }^{1} \mathrm{H}$ NMR spectra suggest that, from the two possible dihydrogen transition states, $\mathrm{H}_{2}$ trans to $\mathrm{C}^{8}$ and $\mathrm{H}_{2}$ trans to $\mathrm{N}$, one of them is more accessible than the other one. In fact, DFT calculations (B3LYP/(6-31g** + SDD)) have revealed that, from the two possible stereochemistries of $\mathrm{OsH}\left\{\kappa^{2}-\mathrm{C}^{8}, \mathrm{~N}\right.$-(quinolinyl) $\}\left(\eta^{2}-\right.$ $\left.\mathrm{H}_{2}\right)\left(\mathrm{P}^{\mathrm{i}} \mathrm{Pr}_{3}\right)_{2}$ (TS), that with the dihydrogen ligand trans disposed to the metalated carbon atom (TSa in Figure $3 ; \mathrm{d}_{\mathrm{H}-\mathrm{H}}=$ $0.88 \AA$ ) is $7.9 \mathrm{kcal}^{-1} \mathrm{~mol}^{-1}$ lower than that containing the coordinated hydrogen molecule trans to the nitrogen atom $\left(\mathbf{T S b} ; \mathrm{d}_{\mathrm{H}-}\right.$ ${ }_{\mathrm{H}}=0.97 \AA$ ). In addition, it should be mentioned that TSa only lies $11.9 \mathrm{kcal}_{\mathrm{mol}}{ }^{-1}$ above 2; a difference that is consistent with the activation energy of the exchange.

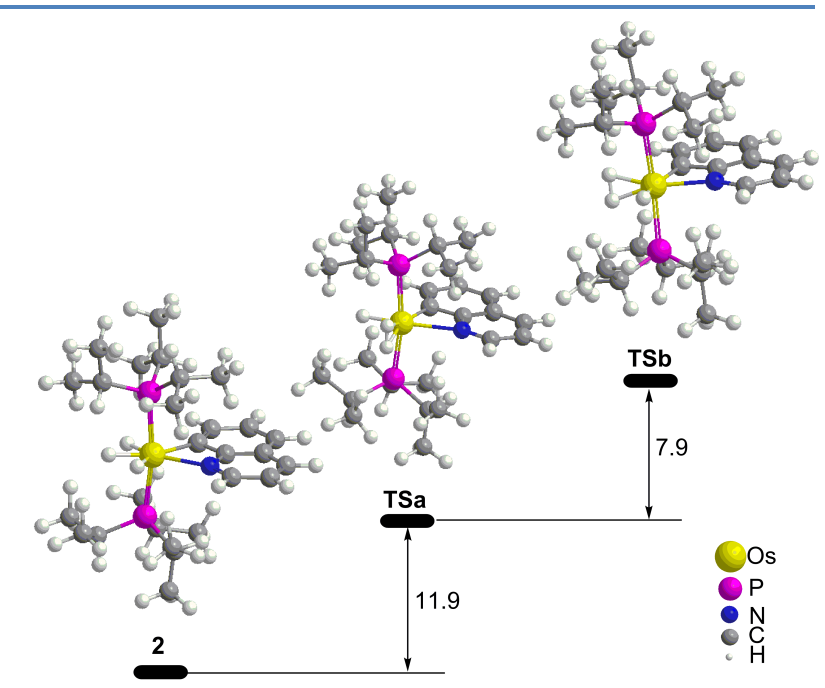

Figure 3. Calculated structures of 2, TSa and TSb using the DFT method (complex, Gibbs energy in kcal.mol ${ }^{-1}$ ). 
The ability of $\mathbf{1}$ for activating the $\mathrm{C}-\mathrm{H}$ bond at 8-position of quinolines is in contrast with the behavior previously reported for the dichloride-dihydride-osmium(IV) complex $\mathrm{OsH}_{2} \mathrm{Cl}_{2}\left(\mathrm{P}^{\mathrm{i}} \mathrm{Pr}_{3}\right)_{2}{ }^{6 \mathrm{a}}$ and the dichloride-hydride-iridium(III) compound $\mathrm{IrHCl}_{2}\left(\mathrm{P}^{\mathrm{i}} \mathrm{Pr}_{3}\right)_{2}{ }^{6 \mathrm{c}}$ which activate the $\mathrm{C}-\mathrm{H}$ bond at 2position of the heterocycles ${ }^{13}$ to finally afford $\mathrm{C}^{2}$ quinolinylidene derivatives bearing an $\mathrm{NH}$ wingtip. The absence of $\pi$-donor ligands in $\mathbf{1}$, such as chloride, which stabilize the metal quinolinylidene bond can explain this difference in behavior. Recent DFT calculations, using AIM and NBO methods, have shown that Os-NHC bonds tolerate a significant $\pi$-backdonation from the metal to the $p_{z}$ atomic orbital of the carbene carbon atom. The $\pi$ accepting capacity is higher than those of the aryl groups and phosphine ligands. ${ }^{14}$ Although complex 1 promotes the activation of the $\mathrm{NC}-\mathrm{H}$ bond of 2-methyl-pyridine, ${ }^{15}$ the $\mathrm{C}-\mathrm{H}$ bond activation at 2-position of quinoline and methyl-quinolines does not take place even when the 8-position is protected with a methyl group. In that case, the $\mathrm{C}\left(\mathrm{sp}^{3}\right)-\mathrm{H}$ bond activation of the methyl substituent of the heterocycle is preferred over the $\mathrm{C}^{2}-\mathrm{H}$ activation. ${ }^{16}$

The reducing character of osmium also appears to be determinant for the $\mathrm{C}-\mathrm{H}$ bond activation at 8-position of the quinolines. Thus, in contrast to $\mathbf{1}$, polyhydrides of oxidizing second row metals, such as the rutenium counterpart $\mathrm{RuH}_{2}\left(\eta^{2}-\right.$ $\left.\mathrm{H}_{2}\right)_{2}\left(\mathrm{PCy}_{3}\right)_{2}{ }^{17}$ and the molybdenum-tetraydride $\mathrm{MoH}_{4}\left(\mathrm{PMe}_{3}\right)_{4},{ }^{18}$ undergo $\eta^{6}$-heterocyclic coordination to subsequently hydrogenate the ring. ${ }^{19}$

In conclusion, the hexahydride complex $\mathrm{OsH}_{6}\left(\mathrm{P}^{\mathrm{i}} \mathrm{Pr}_{3}\right)_{2}$ promotes the direct $\mathrm{C}-\mathrm{H}$ bond activation at 8-position of quinoline and methylquinolines. The absence of $\pi$-donor ligands in the coordination sphere of the metal center and the reducing character of the metallic element appear to be determinant factors for the success of this metal-mediated $\mathrm{C}-\mathrm{H}$ bond activation, which is essential for performing the challenging direct functionalization at 8-position of quinolines.

\section{ASSOCIATED CONTENT}

\section{Supporting Information}

The Supporting Information is available free of charge on the ACS Publications website.

Experimental procedures, analytical data of compounds, crystallographic data (CCDC 1452609 (2) and 1452610 (4), and details of DFT calculations (PDF)

Cristallographic data for compounds $\mathbf{2}$ and $\mathbf{4}$ (CIF)

Cartesian coordinates of calculated compounds (XYZ)

\section{AUTHOR INFORMATION}

\section{Corresponding Author}

*E-mail for M. A. E.: maester@unizar.es.

Notes

Any additional relevant notes should be placed here.

\section{ACKNOWLEDGMENT}

Financial support from the MINECO of Spain (Projects CTQ2014-52799-P and CTQ2014-51912-REDC), the Diputación General de Aragón (E-35), FEDER, and the European Social Fund is acknowledged.

\section{REFERENCES}

(1) (a) Shilov, A. E.; Shul'pin, G. B. Chem. Rev. 1997, 97, 28792932. (b) Lersch, M.; Tilset, M. Chem. Rev. 2005, 105, 2471-2526. (c) Balcells, D.; Clot, E.; Eisenstein, O. Chem. Rev. 2010, 110, 749823.

(2) (a) Ackermann, L. Acc. Chem. Res. 2014, 47, 281-295. (b) Colby, D. A.; Bergman, R. G.; Ellman, J. A. Chem. Rev. 2010, 110, 624655. (c) Mkhalid, I. A. I.; Barnard, J. H.; Marder, T. B.; Murphy, J. M.; Hartwig, J. F. Chem. Rev. 2010, 110, 890-931. (d) Hartwig, J. F. J. Am. Chem. Soc. 2016, 138, 2-24.

(3) Alabau, R. G.; Eguillor, B.; Esler, J.; Esteruelas, M. A.; Oliván, M.; Oñate, E.; Tsai, J.-Y.; Xia, C. Organometallics 2014, 33, 55825596.

(4) McAteer, C. H.; Balasubramanian, M.; Murugan, R. In Comprehensive Heterocyclic Chemistry III; Katritzky, A. R.; Ramsden, C. A.; Scriven, E. F. V.; Taylor, R. J. K. Eds.; Elsevier : Oxford, 2008; Vol 7, pp 309-336.

(5) (a) Stephens, D. E.; Larionov, O. V. Tetrahedron 2015, 71, 8683-8716. (b) Iwai, T.; Sawamura, M. ACS Catal. 2015, 5, 50315040.

(6) (a) Esteruelas, M. A.; Fernández-Alvarez, J. F.; Oñate, E. J. Am. Chem. Soc. 2006, 128, 13044-13045. (b) Lewis, J. C.; Bergman, R. G.; Ellman, J. A. Acc. Chem. Res. 2008, 41, 1013-1025. (c) Esteruelas, M. A.; Fernández-Alvarez, F. J.; Oliván, M.; Oñate, E. Organometallics 2009, 28, 2276-2284.

(7) Konishi, S.; Kawamorita, S.; Iwai, T.; Steel, P. G.; Marder, T. B.; Sawamura, M. Chem. Asian J. 2014, 8, 434-438.

(8) Kwak, J.; Kim, M.; Chang, S. J. Am. Chem. Soc. 2011, 133, 3780-3783.

(9) (a) Kabir, S. E.; Kolwaite, D. S.; Rosenberg, E.; Hardcastle, K.; Cresswell, W.; Grinsdstaff, J. Organometallics 1995, 14, 3611-3613. (b) Arcia, E.; Kolwaite, D. S.; Rosenberg, E.; Hardcastle, K.; Ciurash, J.; Duque, R.; Gobetto, R.; Milone, L.; Osella, D.; Botta, M.; Dastrú, W.; Viale, A.; Fiedler, I. Organometallics 1998, 17, 415-426. (c) Bergman, B.; Holmquist, R.; Smith, R.; Rosenberg, E.; Ciurash, J.; Hardcastle, K.; Visi, M. J. Am. Chem. Soc. 1998, 120, 12818-12828. (d) Din, A. B.; Bergman, B.; Rosenberg, E.; Smith, R.; Dastrú, W.; Gobetto, R.; Milone, L.; Viale, A. Polyhedron 1998, 17, 2975-2984.

(10) (a) Clarck, A. M.; Rickard, C. E. F.; Roper, W. R.; Wright, L. J. J. Organomet. Chem. 1997, 545-546, 619-622. (b) Clark, A. M.; Rickard, C. E. F.; Roper, W. R.; Wright, L. J. Organometallics 1998, $17,4535-4537$.

(11) See for example: (a) Barrio, P.; Castarlenas, R.; Esteruelas, M. A.; Oñate, E. Organometallics 2001, 20, 2635-2638. (b) Eguillor, B.; Esteruelas, M. A.; Oliván, M.; Puerta, M. Organometallics 2008, 27, 445-450. (c) Esteruelas, M. A.; Masamunt, A. B.; Oliván, M.; Oñate, E.; Valencia, M. J. Am. Chem. Soc. 2008, 130, 11612-11613. (d) Crespo, O.; Eguillor, B.; Esteruelas, M. A.; Fernández, I.; GarcíaRaboso, J.; Gómez-Gallego, M.; Martín-Ortiz, M.; Oliván, M.; Sierra, M. A. Chem. Commun. 2012, 48, 5328-5330.

(12) The structure of $\mathbf{4}$ has two chemically but crystallographically independent molecules in the asymmetric unit.

(13) Esteruelas, M. A.; Fernández-Alvarez, F. J.; Oñate, E. Organometallics 2008, 27, 6236-6244.

(14) Bolaño, T.; Esteruelas, M. A.; Fernández, I.; Oñate, E.; Palacios, A.; Tsai, J.-T.; Xia, C. Organometallics 2015, 34, 778-789.

(15) Esteruelas, M. A.; Forcén, E.; Oliván, M.; Oñate, E. Organometallics 2008, 27, 6188-6192.

(16) Baya, M.; Eguillor, B.; Esteruelas, M. A.; Lledós, A.; Oliván, M.; Oñate, E. Organometallics 2007, 26, 5140-5152.

(17) Borowski, A. F.; Sabo-Etienne, S.; Donnadieu, B.; Chaudret, B. Organometallics 2003, 22, 1630-1637.

(18) Zu, G.; Pang, K.; Parkin, G. J. Am. Chem. Soc. 2008, 130, 1564-1565.

(19) Bachrach, M.; Marks, T. J.; Notestein, J. N. ACS Catal. 2016, 6, 1455-1476. 


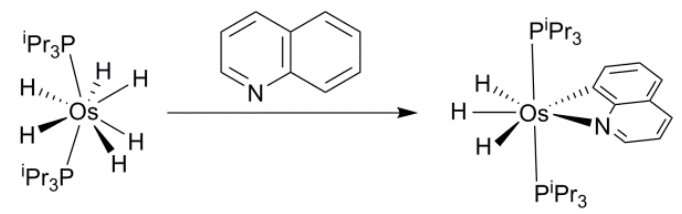

